Article

\title{
Economic Power Schedule and Transactive Energy through an Intelligent Centralized Energy Management System for a DC Residential Distribution System
}

\author{
Jingpeng Yue ${ }^{1, *}$, Zhijian $\mathrm{Hu}^{1}$, Chendan $\mathrm{Li}^{2}{ }^{2}$, Juan C. Vasquez ${ }^{2}$ and Josep M. Guerrero ${ }^{2}$ (D) \\ 1 School of Electrical Engineering, Wuhan University, Wuhan 430047, China; zhijian_hu@163.com \\ 2 Department of Energy Technology, Aalborg University, Aalborg 9220, Denmark; che@et.aau (C.L.); \\ juq@et.aau.dk (J.C.V.); joz@et.aau.dk (J.M.G.) \\ * Correspondence: 2015102070024@whu.edu.cn; Tel.: +86-137-1797-6970
}

Academic Editor: Angela Russo

Received: 20 May 2017; Accepted: 27 June 2017; Published: 3 July 2017

\begin{abstract}
Direct current (DC) residential distribution systems (RDS) consisting of DC living homes will be a significant integral part of future green transmission. Meanwhile, the increasing number of distributed resources and intelligent devices will change the power flow between the main grid and the demand side. The utilization of distributed generation (DG) requires an economic operation, stability, and an environmentally friendly approach in the whole DC system. This paper not only presents an optimization schedule and transactive energy (TE) approach through a centralized energy management system (CEMS), but also a control approach to implement and ensure DG output voltages to various DC buses in a DC RDS. Based on data collection, prediction and a certain objectives, the expert system in a CEMS can work out the optimization schedule, after this, the voltage droop control for steady voltage is aligned with the command of the unit power schedule. In this work, a DC RDS is used as a case study to demonstrate the process, the RDS is associated with unit economic models, and a cost minimization objective is proposed that is to be achieved based on the real-time electrical price. The results show that the proposed framework and methods will help the targeted DC residential system to reduce the total cost and reach stability and efficiency.
\end{abstract}

Keywords: optimization schedule; transactive energy; direct current residential distributed system; living homes; direct current droop control; centralized energy management system; electrical price

\section{Introduction}

DC power systems are gaining more and more attention for distributed systems and microgrids, due to their advantages. On the energy supply side, many DG systems, such as photovoltaics, fuel cells and batteries present natural DC output. Besides, on the load side, many appliances such as computers, LED lights, and electric vehicles are in facts natural DC loads [1-3]. Obviously, it is ideal to power DC loads with DC supply. Moreover, a DC system has the advantage of being able to cope with inherent problems related to the alternating current (AC) system, such as the synchronization of the distributed generators, three-phase imbalances, inrush currents, reactive power flow, and harmonic currents [4]. Nowadays, DC microgrids are found in many places and the development of technologies for future intelligent DC microgrids is also being deployed for the highly efficient integration of distributed generation and modern electronic loads [5,6]. In this paper, the distributed system consists of DC living homes. A smart DC living home has been established at Aalborg University, where ZigBee communication and remote control are deployed [7]. 
Smart DC distributed power systems, integrated together with DG, controlled loads, energy storage systems (ESS), etc., require more and more intelligent economical operation and stability. As the types of renewable sources increase in penetration and present an efficient and economical utilization of resources, there is the idea that a TE framework needs to be considered in the future power system $[8,9]$. The transition to and advance of communication in microgrid technologies result in end-customer participation. TE not only permits a user to respond to economic incentives or market policies, but also allows prosumers and neighbors to gain economic advantages and save energy through cost cost-effective and reliable management solutions [10,11]. In this sense, the expected whole energy system will be more interactive, intelligent, and flexible. The transactive grid has begun in America, where residential consumers can buy and sell solar energy through a scale solar project [12]. A comprehensive framework for residential buildings was proposed in a recent study [13] and was implemented in an Australian residential building.

An energy management system (EMS) of a distributed system is the given objective and an interdisciplinary topic. An EMS can be implemented in a centralized or decentralized way, both of which have disadvantages and advantages $[14,15]$. According to the special system type-such as commercial, residential or military - a proper CEMS can be designed to not only supervise and control the entire system, but also to gather and manage information, and to optimize and provide expert dispatch to achieve an efficient and economical manner. However, a CEMS also has disadvantages, for example, a fault in the central unit of the CEMS may cause a breakdown of the whole system. Meanwhile, decentralized control and management of microgrids and distributed systems has also been implemented. In the context of a TE framework, a distributed EMS addresses the short time operation in hybrid AC-DC microgrids [16]. Through decentralized management, to which the agent technology mainly tends in recent years, a multi-agent system is introduced. This system is described in several papers [17-19], and generally includes a database gateway agent, date monitoring agent, operator agent, distributed energy resource (DER) gateway agent, schedule agent, and another agent. Like the CEMS, the agent system faces some inherent problems, such as voltage and power coordination in the distributed network.

According to the definition by the U.S. Department of Energy (DOE), a distributed power system and microgrid can be delineated as a group of interconnected loads and DGs within clearly defined electrical boundaries that act as a single controllable entity with respect to the grid [20]. In a conventional power system arrangement, the desired voltage is generally maintained by controlling reactive power. Due to the DER penetration and operation when connected to the grid, the use of a converter or inverter is mandatory in a DC distributed system. Voltage stability is also a crucial issue in grid arrangement [21]. In DC power systems, the regulating converter adjusts the system bus voltage. The converter and inverter are responsible not only for transactive energy between the grid and distributed system, but also for voltage stability in the distributed network [22-24]. In this sense, the DC voltage droop scheme can be used to inject power to DC buses in the control process. In this work, we use adaptive DC droop control to adjust the voltage and align with the real-time power schedule.

Given the above, this work will mainly achieve the following: firstly, set out that economic dispatch and TE can be achieved through a CEMS that manages the power system of DC living homes. Secondly, establish whether primary voltage droop control of the converter can achieve the desired stability and accuracy level. The rest of the paper is organized as follows: in Section 2, the structures of a DC RDS consisting of a DC living home and CEMS are introduced. Control and implementation systems are presented in Section 3. An economic optimization analysis for components of the system is found in Section 4. A case study demonstrates the economical operation of a DC DRS in Section 5. Finally, Section 6 provides the conclusion and directions for future work. 


\section{Structures of the DC Residential Distributed System (RDS)}

An RDS mainly consisting of DC living homes with integrated electrical and information infrastructure is shown in Figure 1. Each living home is equipped with a smart meter, and is interconnected with the main grid, an intelligent CEMS, and the electrical market. Customers can receive power from both renewable energy sources and the external grid. Besides, these operators are also willing to inject extra power into the grid to share through TE system. The following sections introduce the main power framework and CEMS.

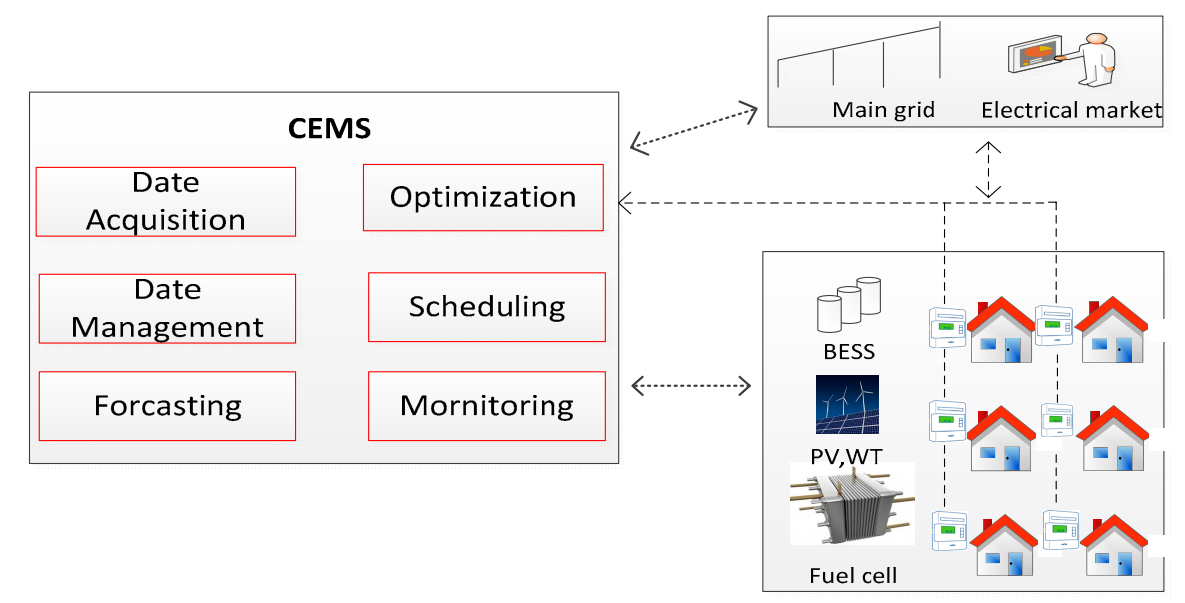

Figure 1. Structure of a DC Residential Distribution System (RDS).

\subsection{Power Architecture of the DC RDS}

The power system of the DC RDS is framed by distributed generators (photovoltaic (PV) panels, wind turbines (WT), and a fuel cell), energy storage devices (Li-ion batteries), converters, DC buses, and loads.

(1) Distributed generators: composed of PV panels and wind turbines in series or in parallel. The maximum peak power tracking (MPPT) technology is implemented to emphasize high efficiency in the DC RDS.

(2) Converters: these are responsible for the charge and discharge of buses with loads and generations. A unidirectional DC-DC converter is used for connecting PV and DC load with DC buses with different voltage levels; a bi-directional DC-DC converter is used for connecting batteries energy storage system (BESS) with $48 \mathrm{~V}$ DC bus. An AC-DC converter is used for AC distributed power with DC bus. The DC residential area is connected to the utility grid through a centralized bi-direction converter.

(3) Buses: all system components including DGs, loads, ESS, etc., are connected to multi-voltage lever buses by converters. DC Buses with $230 \mathrm{~V}, 48 \mathrm{~V}, 24 \mathrm{~V}$ and $12 \mathrm{~V}$ are deployed in this DC RDS [25].

(4) Energy storage system (ESS): composed of advances in the Li-ion battery technology in parallel or in a series, which can not only be utilized to absorb excessive power and to carry out charging and discharging as the signal from the EMS, but also has a fast response time following the cooperation control [26,27].

(5) Information system (IS): this, with aid of wireless communication and the smart meter, is imperative for achieving TE. The DC living home lab in Aalborg is equipped with a Zigbee smart device that is flexible and comfortable for user experience [28]. 


\subsection{Centralized Energy Management System}

In a DC residential distribution system, the function of the EMS can be implemented in a centralized way. This RDS follows a CEMS similar to the structure for a microgrid [29]. The CEMS consists of a central controller and wireless communication that is provided with the relevant information from the meters of different actors in the DC system environment. Then, according to the various objectives, the CEMS is identified for real-time optimization in order to dispatch the DER unit in the DC system. In detail, the responsibilities of the CEMS are:

- Collecting and managing local information, e.g., load date, generation power, smart meter dates.

- $\quad$ Forecasting DER information, e.g., load, the power of WTs, PVs.

- Main grid information, e.g., real-time electrical price, demand response information.

- Monitoring the whole system, e.g., state of charge of the ESS, security and reliability constraints of the DC residential system.

- The expert system, e.g., optimization algorithms for various objectives, constraints and operational limits of units.

- The output variables of the EMS are the reference values for the control system (e.g., output power and/or terminal voltage) for each dispatchable DER.

\section{The Control and Implementing System in the DC System}

Apart from the optimization schedule, the DC system is technically suited for providing control reserve, allowing tracking of the command and short response time.

\subsection{Adaptive Droop Control in the DC Distributed Power System (Network)}

A hierarchical approach could be adopted for the design of the control system of a DC residential system, which includes primary, secondary, and tertiary control. Converter control is based on voltage droop control in order to share power for DGs and be responsible for tracking DC voltage reference. The secondary control is for removing voltage deviation and ensuring reliable operation, the tertiary control is responsible for economical and coordinated operation, and for the host grid that is related to transactive energy control. In this work, we mainly consider the primary control. PV and WT are preferred to inject maximum power and operate in MTTP mode, however, the output voltages of DERs in common buses should be the priority. Bidirectional and directional converters are mandatory to adapt the out voltages through the adaptive droop loop. The equivalent circuit of voltage droop control for three parallel voltage source converters is shown in Figure 2.

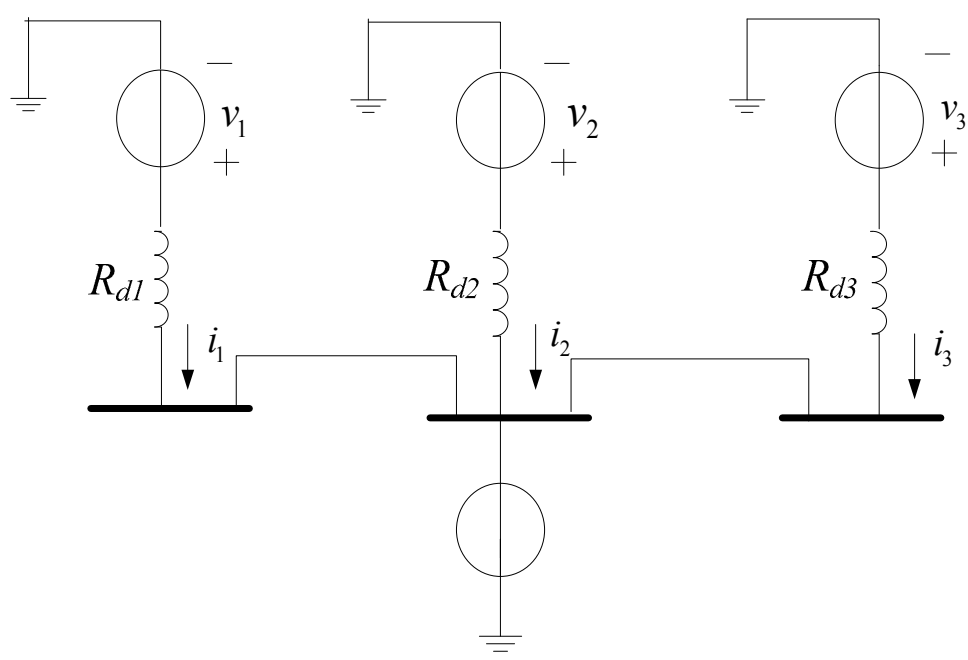

Figure 2. Equivalent circuit of parallel distributed generation (DG). 
Figure 2 shows the equivalent circuit of three parallel voltage source converters to accomplish current sharing in a distributed way. The output voltage reference of every converter should follow the voltage droop characteristic defined with virtual impedance. The grid-forming converter in this system can be expressed as [13]:

$$
\begin{gathered}
v_{o, i}=v_{r e f, i}-R_{d, i} \times i_{0} \\
R_{d}=1 / \sum_{i=1}^{n} \frac{1}{R_{d, i}}
\end{gathered}
$$

where $v_{0, i}$ is the voltage reference of the converter $I, i_{0}$ is the output current of the converter $i, v_{r e f, i}$ is the reference voltage of the droop circuit, and $R_{d}$ is the virtual impedance value. For the distributed unit $i$ connected with bus, the power generated by unit $i$ can be written as

$$
P_{D G, i}=v_{0, i} \cdot i_{0, i}
$$

The droop circuit in a DC power system is converter resistance, so the virtual impedance can be considered a constraint. As per Kirchhoff's current law and Equations (1) and (3), in a voltage droop circuit this can be written as

$$
P_{D G, i}=v_{r e f, i} \cdot P_{D G, i} / v_{o, i}-R_{d, i} \cdot P_{D G, i}
$$

where $P_{D G, i}$ is the power of a dispatchable unit $i$ in the network, $v_{r e f, i}$ is the reference voltage of various buses, and $R_{d, i}$ is the virtual resistance in the voltage droop circuit. According to the signal of the real-time power scheduling, we can program primary control by optimizing the adaptive virtual impedances $R_{d}$. Assuming $\varepsilon$ is the maximum allowed voltage deviation, which is generally $\pm 5 \%$ deviation, $R_{d}$ and $v_{\text {ref }}$ are designed as:

$$
\begin{gathered}
v_{r e f}=v_{n}-\varepsilon / 3 \\
R_{d}=\varepsilon / i_{\max }
\end{gathered}
$$

where $v_{n}$ is the output voltage and $i_{\max }$ is the maximum output current. The equations show the equivalent circuit of three parallel voltage source converters. In the processing of schedule, the droop control level adjusts the voltage reference provided to the inner current and voltage control loops. Every bus voltage should follow the output voltage of every converter defined with virtual impedance.

\subsection{Flow Chart of Schedule and TE}

The CEMS is core to the proposed processing, the flow chart is mainly contains two stages (Figure 3). In the first stage, the intelligent schedule decision is made by expert system. In the second stage, the dispatching and lower control are implemented accordingly.

The operation of the schedule and transaction energy is usually subject to various objectives and constraints, which are not only electrical but also relate to the environment and economic issues. In this work, we mainly consider the cost minimization of the whole system based on the real-time price from the electrical market.

Based on the power flow of the schedule, in order to coordinate the units of the system in a highly efficient way and keep bus voltage stability, the optimization of virtual resistance (VR) should be calculated according to Equations (1)-(4) for adaptive droop control implementation. As the penetration of DER, injection power to the grid may cause a reduction or a rise in voltage. Some international standards such as international organization for standardization (IEEE) 1547 and 2030 define the limits for DC injection [30]. In this work, the bus voltage cannot cause a voltage fluctuation greater than $\pm 5 \%$. 


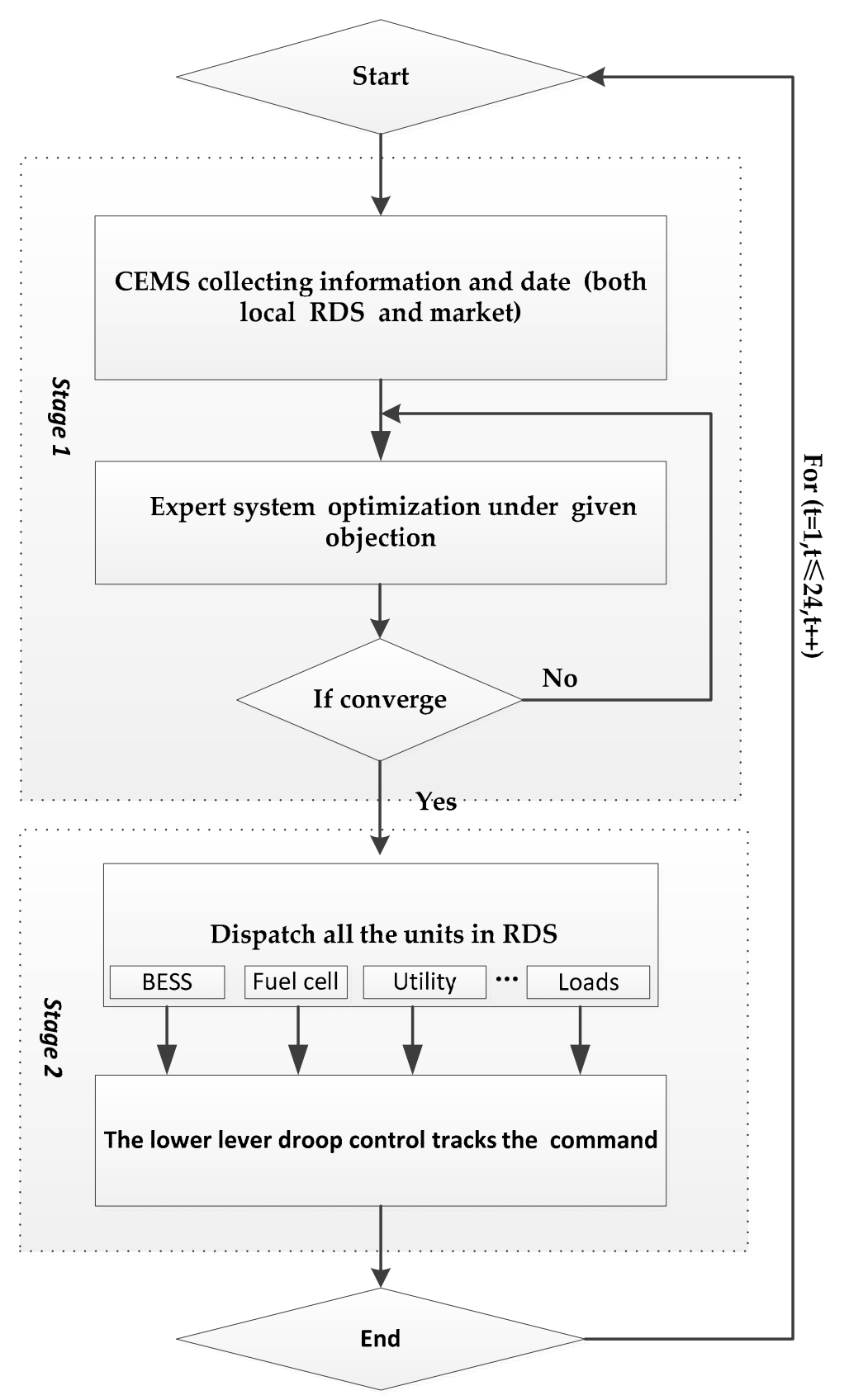

Figure 3. Dispatch mechanism of a centralized energy management system (CEMS).

\section{Optimization for Economic Operation in the DC Residential System}

\subsection{Cost Composition in the DC System}

(1) Cost of utility

With the development of bidirectional communication technology in smart grids, the transactive energy between the constraints grid and the distribution grid can improve economic efficiency. In other words, customers can not only buy electrical energy from the utility but also sell energy to the main grid, based on the transactive mechanism. Based on the real-time price observed from the electrical 
market, the operator of a DC residential distribution system could make a real-time demand response and optimization schedule. The cost of utility in a control cycle can be modeled as:

$$
\begin{gathered}
C_{u t i l i t y, i}=\left\{\begin{array}{l}
f_{\text {buy }} P_{u t i l i t y} \cdot \Delta t_{i}, P_{u t i l i t y}>0 \\
f_{\text {sell }} P_{u t i l i t y} \cdot \Delta t_{i}, P_{u t i l i t y}<0
\end{array}\right. \\
C_{\text {utility }}^{\text {total }}=\sum_{i=1}^{T} C_{u t i l i t y, i}
\end{gathered}
$$

where $f_{b u y}$ is the real-time price from an electrical market; $f_{\text {sell }}$ is the electrical price subsidy for power from a DC distributed system to the grid; $P_{u t i l i t y}$ is the power between the grid-to-DC distribution system, which is positive when the DC distribution system absorbs energy from the grid, and negative when DC distribution system contributes energy to grid; $\mathrm{T}$ is the number of optimization intervals; $\Delta t_{i}$ is the length of the $i$-th time interval; and $C_{u t i l i t y}^{\text {total }}$ is the total utility cost of all optimization intervals.

(2) Cost of fuel cell

The generation cost (excluding renewable generation) can be modeled by the well-known quadratic function of output power as in Equation (9) [1], so the cost of the fuel in the system can be modeled as in Equation (10)

$$
\begin{gathered}
C_{F}=\alpha P_{F}^{2}+\beta P_{F}+\gamma \\
C_{F}^{\text {total }}=\sum_{i=1}^{T}\left(\left(\alpha P_{F}^{2}+\beta P_{F}+\gamma\right) \cdot \Delta t_{i}\right)
\end{gathered}
$$

where $\alpha, \beta, \gamma$ are constants, $P_{F}$ is the output power of the fuel cell, $\Delta t_{i}$ is the length of the $i$-th time interval, and $C_{F}^{\text {total }}$ is the total fuel cell cost of all optimization intervals.

(3) Life loss of BESS

In a conventional way, energy circulation can influence the life loss of a Li battery. Supposing the temperature is constant, the relationship between circulation number $L$ and discharge power $E_{i}$ in $i$-th follows Equation (11) [31]. When the self-discharge-charge is ignored, the total discharge energy equals the charging energy in one circulation. In this sense, the life loss in the circulation can be equal to the cost of the BESS. In this work, a cost coefficient is used to build the relationship between the energy circulation and cost of BESS, which is shown in Equations (12) and (13). Thus the reasonable schedule of charge and discharge power will be beneficial to the life of BESS.

$$
\begin{gathered}
L=-a \cdot\left(E_{i} / E_{b}\right)+b \\
C_{\text {bess }}=\left\{\begin{array}{l}
L \cdot p_{\text {bess }} \cdot \Delta t_{i}, p_{\text {bess }} \geq 0 \\
L \cdot\left|p_{\text {bess }}\right| \cdot \Delta t_{i}, p_{\text {bess }}<0
\end{array}\right. \\
C_{\text {bess }}^{\text {total }}=\sum_{i=1}^{T} C_{\text {bess }, i}
\end{gathered}
$$

where $E_{b}$ is the rated capacity of $L i$ storage batteries, and the a and $\mathrm{b}$ constant are both positive. When the battery is charging; the value of $p_{\text {bess }}$ is positive, otherwise it is negative. The costs in one period are the sum of $i$-th.

\section{(4) Renewable energy cost}

Supporting the customers of the DC residential distribution system are the investors in the renewable energy sources (RES); the cost of RES is free and considered zero. To maximize the RES, the design of the control including the MTTP and strategy of operation are economic. 


\section{(5) Power Loss}

The power loss depends on specific cases and detailed information about the system, e.g., the length of cables, various converters, devices and generators. As the control order is implemented by the converters, which are the main source of power losses, we can consider the power loss that takes place in converter devices in order to evaluate the power loss of a DC residential distributed system. The maximum design value allowed is usually a unit of $10 \%$ in microgrids. The power losses can be written as follows:

$$
C_{\text {loss }}^{\text {total }}=f_{b u y} \sum_{i=1}^{T} \eta_{i c} \cdot P_{i c} \cdot \Delta t_{i}
$$

where the $\eta_{i c}$ is the efficient of the converters, and $P_{i c}$ is the output power of the converters.

\subsection{Objective Function}

The objective of this study is to minimize the total operation cost in $24 \mathrm{~h}$ based on the real-time electrical price, which can be written as:

$$
\min C_{\text {system }}^{\text {total }}=f\left(C_{\text {utility }}^{\text {total }}+C_{F}^{\text {total }}+C_{\text {loss }}^{\text {total }}+C_{\text {bess }}^{\text {total }}\right)
$$

where the total cost can be calculated through Equations (8), (10), (13) and (14), which is a nonlinear equation.

\subsection{Constraints}

Constraints include each unit and the whole system constraint.

(1) System constraints

According to the power balance of the system, constraints can be written as:

$$
P_{p v}+P_{w t}+P_{u t i l i t y}+P_{F}-P_{\text {ess }}-P_{\text {load }}-P_{\text {loss }}=0
$$

(2) BESS charge-discharge strategy and constraints

Reasonable scheduling of the charging and discharging power of the energy storage system (ESS) is beneficial to the extension of the life of the ESS. Assume that the discharge capacity is equal to the charge capacity. The energe state of the charge and discharge are written as (17)-(20), where $\eta_{c}$ is charge efficiency, $\eta_{d}$ is discharge efficiency, $E_{t}$ is the capacity of BESS.

$$
\begin{gathered}
E_{t+1}=E_{t}+\eta_{c} P_{b s s, t} \cdot \Delta T \\
E_{t+1}=E_{t}+P_{b s s, t} / \eta_{d} \cdot \Delta T \\
\sum_{t=t_{a}}^{t=t_{b-1}} E_{t}<E_{t+1}<0.8 E_{\max } \\
-0.8\left(E_{\max }-\sum_{t=t_{a}}^{t=t_{b-1}} P_{t} \times 1_{t}\right) / \Delta T<P_{t_{b}}<0.8\left(E_{\max }-\sum_{t=t_{a}}^{t=t_{b-1}} P_{t} \times 1_{t}\right) / \Delta T
\end{gathered}
$$

(3) Other constraints

Each unit should keep its capacity limits; the utility and fuel cell can be expressed as follows: Inequity constraints:

$$
\begin{gathered}
P_{u t i l i t y, \min }<P_{u t i l i t y, i}<P_{u t i l i t y, \max } \\
0<P_{F, i}<P_{F, \text { max }}
\end{gathered}
$$


The optimization schedule problem is a mixed integer and non-linear formulation program, so the methodology for the solution can use various inequality optimization methods in the expert system. In the constraints system, the optimization result is achieved after the power flow converges. In this work, we solve the problem using sequential quadratic programming to make a lot of iterations in order to find the results.

\section{Case Study}

In this section, we present a 5-bus DC residential system model as shown in Figure 4 to verify the proposed method. The bus voltage standard includes $230 \mathrm{~V}, 48 \mathrm{~V}, 24 \mathrm{~V}$ and $12 \mathrm{~V}$. Meanwhile, the unit data will be collected and processed through a CEMS, which also commands the schedule and control.

In this work, the CEMS is responsible for the RES, bus load and market data process, the details of data collection are shown in the Appendix A. Figure 5 plots the prediction generation of WT and PV constraints from Table A1 in the Appendix A. The 24-h real-time electrical price from the Nord pool electrical market was taken as a case study, which contains the constraints from Table A2 in the Appendix A and the plot given in Figure 6. The loads of different voltage level buses is shown in Figure 7. To achieve the objective of minimizing costs, and as a result of the constraints of the real-time units listed in Table A3 of the Appendix A, the optimization method of a sequential quadratic program makes a lot of iterations in order to find the optimization results for cost minimization. The results of the optimized power schedule are shown in Figure 8. The schedule contains the charge-discharge of ESS and the power flow of the fuel cell and utility, and also satisfied the constraints. The economic consumption for the whole day is shown in Figure 9. The comparison shows that the total cost has been reduced by optimally scheduling the resources.

The CEMS is responsible for computing and implementing the optimized schedule. Consideration of voltage stability, adaptive VR for converters of ESS, and utility and fuel cell constraints for daily control operations are shown in Figure 10. Meanwhile, Figure 11 shows that the voltage vacillation is within the allowable range. The results show that a DC RDS can reach stability and an economical level that will be of benefit for both customers and grid.

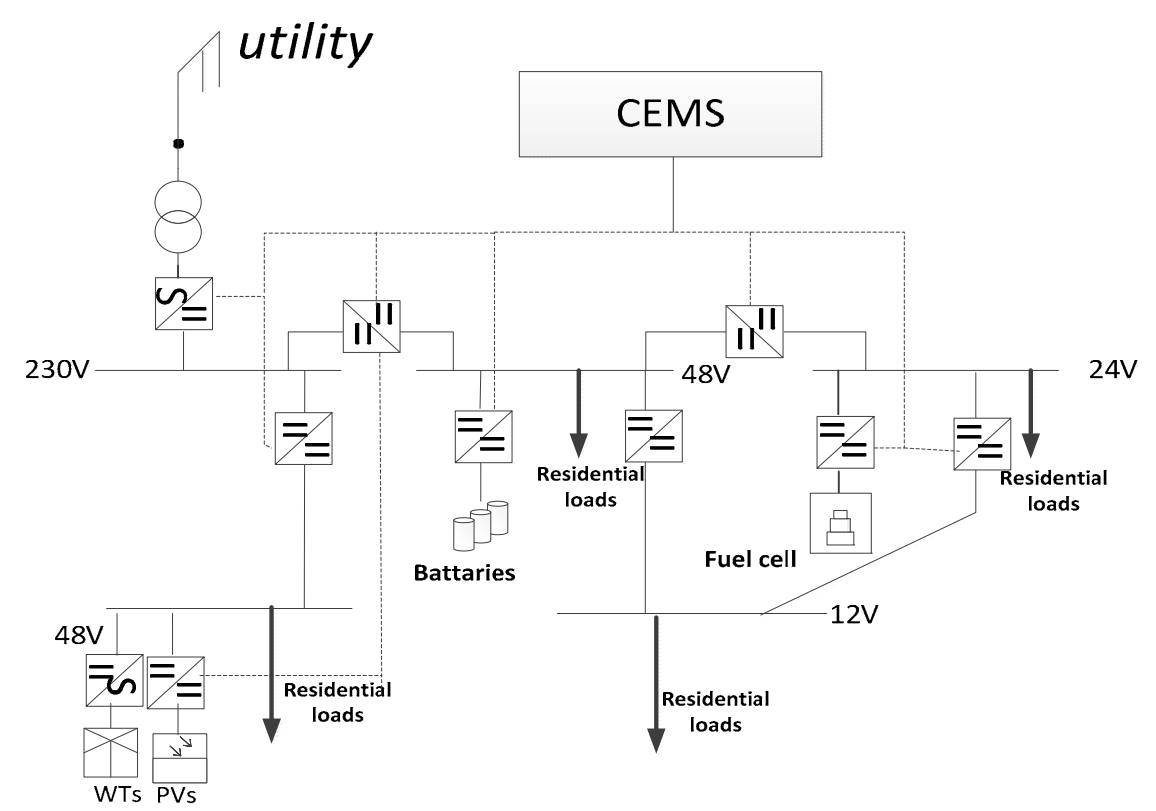

Figure 4. Structure of the 6-bus distributed residential power system. 


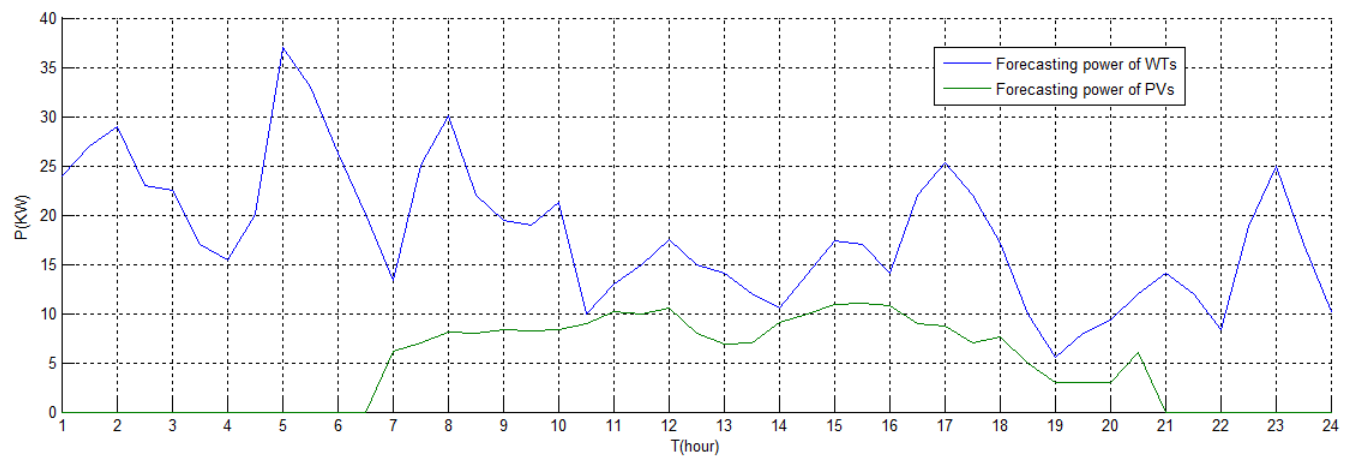

Figure 5. Distributed generation (DG) power in the DC residential system.

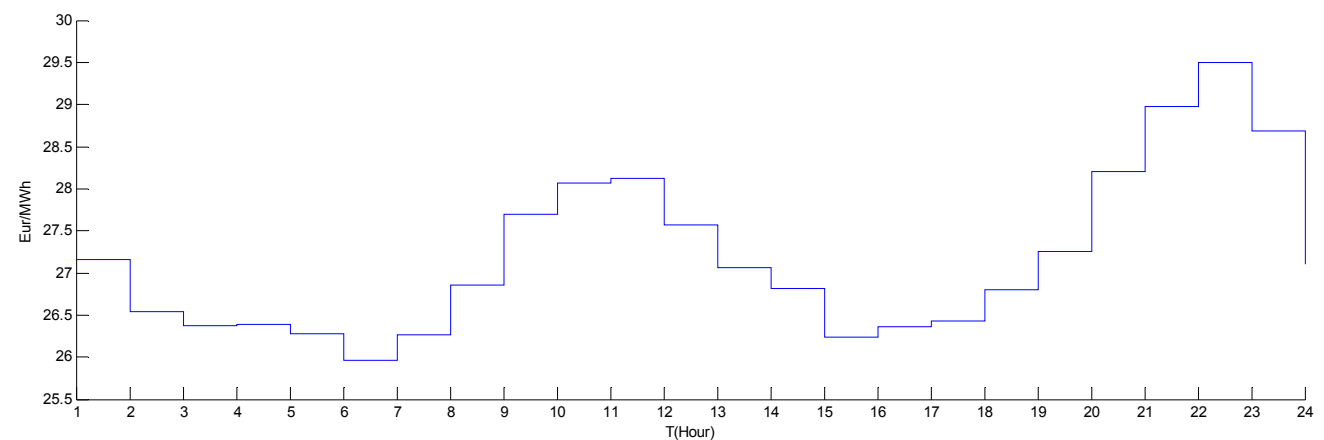

Figure 6. Real-time prices from the Nord pool market.

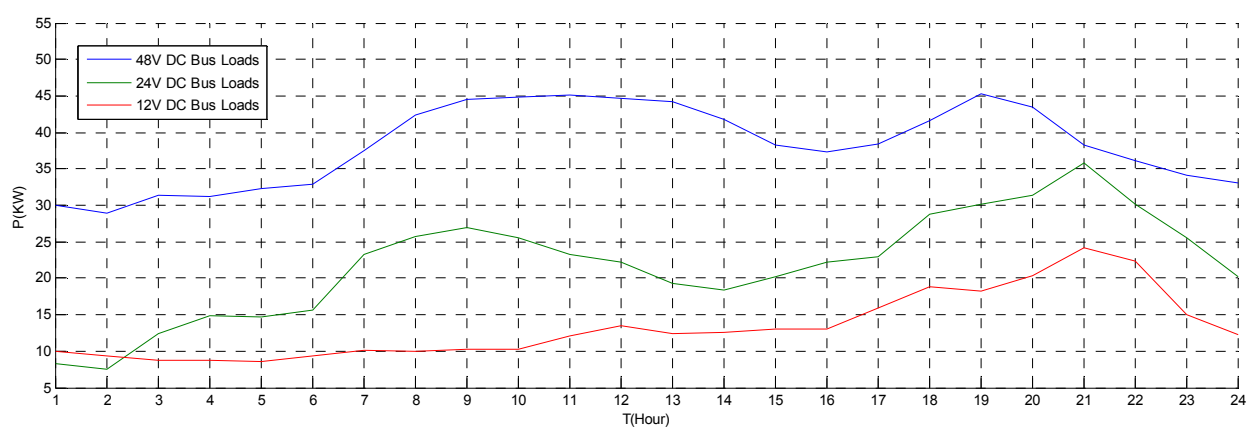

Figure 7. Loads of DC bus in the residential system.

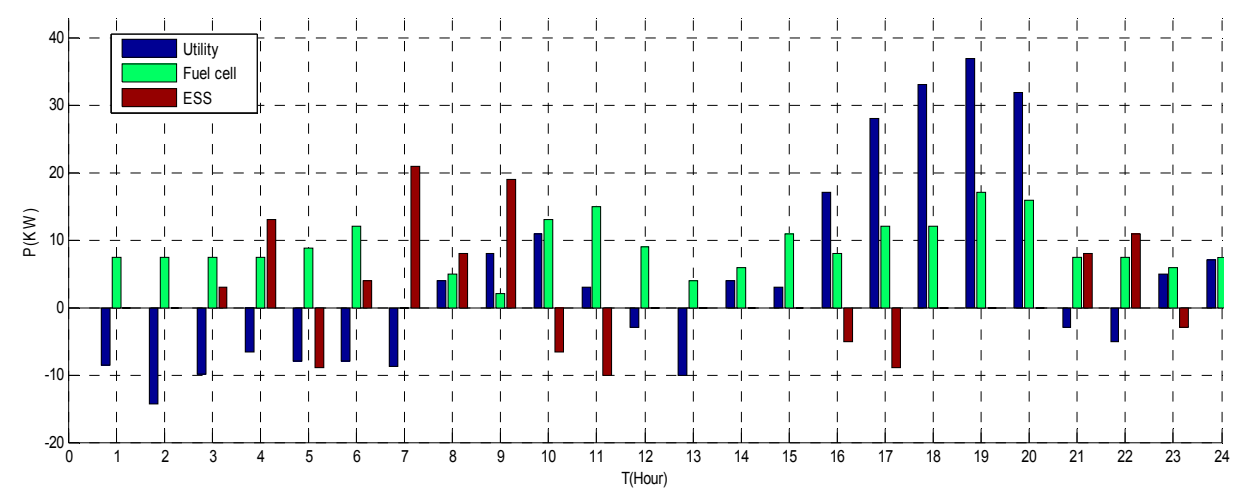

Figure 8. The hourly schedule of units. 


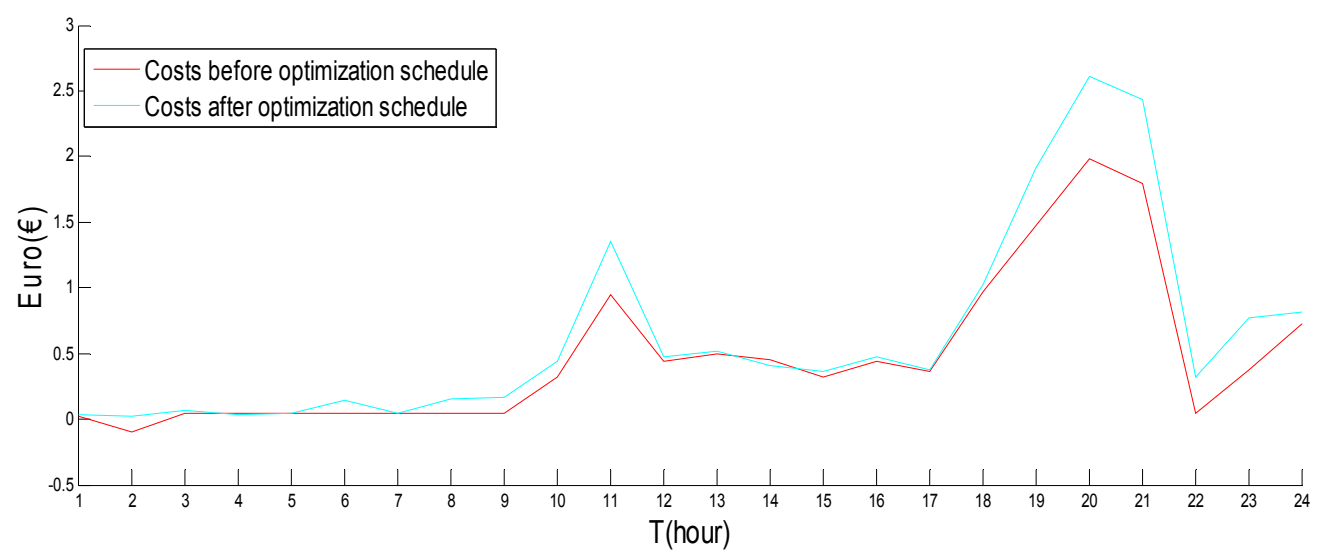

Figure 9. The costs compared to the DC residential system.

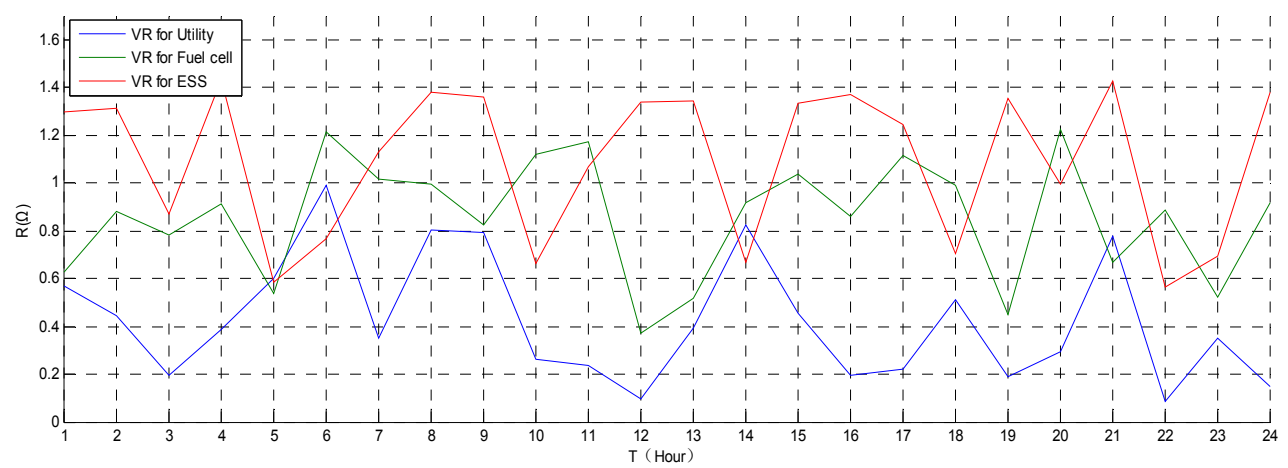

Figure 10. The VR implementation of converters in droop control.

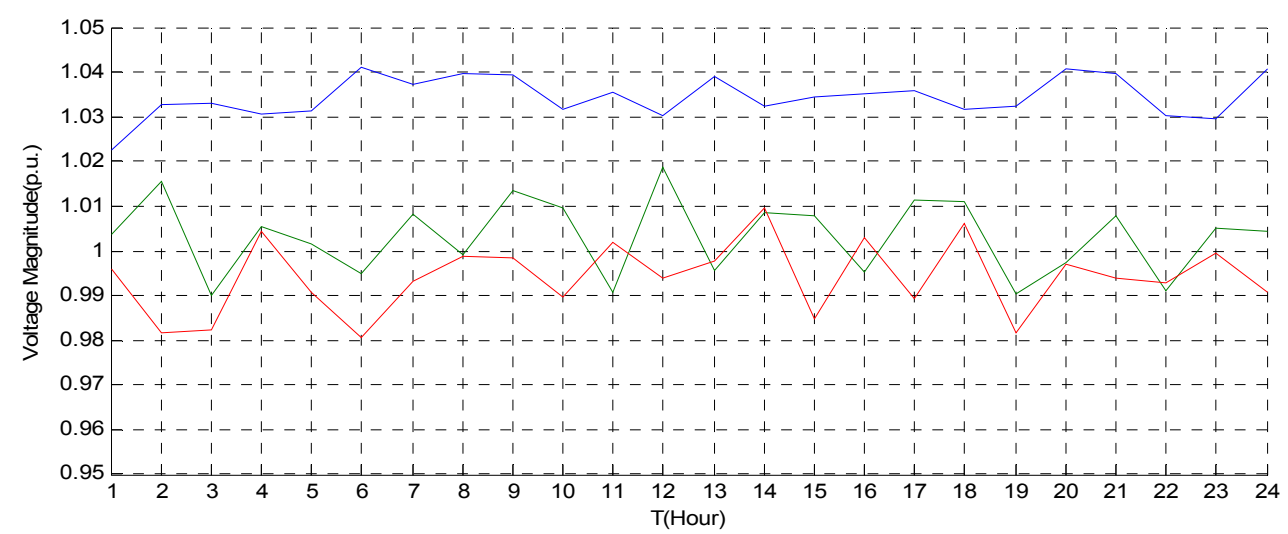

Figure 11. The voltage deviation of droop units.

\section{Conclusions and Future Work}

As a promising power system, an RDS consisting of DC living homes can be managed through a CEMS, which is responsible for collecting data, predicting, optimizing, control, etc. This work presents a schedule for economical processing and TE with the main grid. The work mainly includes an economical schedule and stability operation; the mathematical models of the main components of the DC power system, which can be formulated to optimize the power schedule for the objective of cost minimization based on the real-time electrical price; and the results, which show the optimized hourly power schedule that can reduce the total cost. Meanwhile, droop control can track the command and 
control the converter voltage of main units. Within daily schedule processing, the voltage variation is kept in the stable range, which is of benefit to the stability of the whole system.

Following-up, the precise adjustment of bus voltage and power flow will be evaluated. The distributed energy management system will also be compared with the CEMS. Future work will also track to several contents. It will consider, for example, thermal and controlled loads, the optimizing schedule of an electrical vehicle in a DC system, and the resources of a DC RDS that can also participate in bidding in the competitive electrical market.

Acknowledgments: This work was in part supported by Wuhan University Ph.D. Short-time Mobility Program.

Author Contributions: Jingpeng Yue carried out the main research tasks and wrote the manuscript; Zhijian Hu conceived and designed the model; Chendan Li provided the data and modified the model; Juan C. Vasquez, and Josep M. Guerrero promoted the results.

Conflicts of Interest: The authors declare no conflict of interest. The founding sponsors had no role in the design of the study; in the collection, analyses, or interpretation of data; in the writing of the manuscript, and in the decision to publish the results.

\section{Appendix A}

The load data of the DC bus and the generation data of distributed renewable generation were collected from OpenEI. The real-time price was collected from Nord pool.

Table A1. Load and renewable generators (kW).

\begin{tabular}{cccccc}
\hline Time & Load $(\mathbf{4 8} \mathbf{~ V )}$ & Load $(\mathbf{2 4} \mathbf{~ V )}$ & Load $(\mathbf{1 2} \mathbf{~ V )}$ & WT & PV \\
\hline $00-01$ & 30.1 & 8.3 & 10 & 24 & 0 \\
$01-02$ & 28.5 & 7.4 & 9.4 & 29 & 0 \\
$02-03$ & 31.9 & 12.6 & 8.7 & 22.55 & 0 \\
$03-04$ & 32.2 & 31.7 & 8.6 & 15.43 & 0 \\
$04-05$ & 33.4 & 14.9 & 8.3 & 37.05 & 0 \\
$05-06$ & 33.9 & 15.5 & 9.2 & 26.22 & 0 \\
$06-07$ & 37.2 & 24.3 & 10.1 & 13.34 & 6.12 \\
$07-08$ & 42.2 & 25.8 & 10.1 & 30.06 & 8.09 \\
$08-09$ & 44.8 & 27.1 & 10.5 & 19.4 & 8.33 \\
$09-10$ & 45 & 26 & 10.8 & 21.32 & 8.4 \\
$10-11$ & 45.2 & 23.7 & 13.8 & 0.33 & 10.23 \\
$11-12$ & 44.6 & 24 & 14.2 & 17.56 & 10.57 \\
$12-13$ & 43.9 & 19.6 & 13.8 & 14.03 & 6.88 \\
$13-14$ & 42 & 18 & 14.1 & 10.53 & 9.06 \\
$14-15$ & 38 & 20 & 14.4 & 17.32 & 10.89 \\
$15-16$ & 37.3 & 23.3 & 14.8 & 14.06 & 10.75 \\
$16-17$ & 38.2 & 24 & 15.4 & 25.3 & 8.77 \\
$17-18$ & 42.8 & 28.7 & 19.3 & 17.15 & 7.65 \\
$18-19$ & 45 & 30.3 & 18.8 & 5.5 & 3.03 \\
$19-20$ & 43.9 & 32.4 & 20.2 & 9.35 & 2.98 \\
$20-21$ & 38.8 & 35.2 & 28.6 & 14.09 & 0 \\
$21-22$ & 36.6 & 30.1 & 23.4 & 8.33 & 0 \\
$22-23$ & 34.7 & 25.1 & 15 & 24.9 & 0 \\
$23-24$ & 33.3 & 20.3 & 13 & 10.23 & 0 \\
\hline
\end{tabular}

Table A2. Real-time electrical price from Nord POOL (Eur/MWh).

\begin{tabular}{lcccccccccccc}
\hline Time & $\mathbf{0 0 - 0 1}$ & $\mathbf{0 1 - 0 2}$ & $\mathbf{0 2 - 0 3}$ & $\mathbf{0 3 - 0 4}$ & $\mathbf{0 4 - 0 5}$ & $\mathbf{0 5 - 0 6}$ & $\mathbf{0 6 - 0 7}$ & $\mathbf{0 7 - 0 8}$ & $\mathbf{0 8 - 0 9}$ & $\mathbf{0 9 - 1 0}$ & $\mathbf{1 0 - 1 1}$ & $\mathbf{1 1 - 1 2}$ \\
\hline Price & 27.16 & 26.54 & 26.37 & 26.39 & 26.28 & 25.96 & 26.27 & 26.85 & 27.69 & 28.06 & 28.12 & 27.57 \\
Time & $12-13$ & $13-14$ & $14-15$ & $15-16$ & $16-17$ & $17-18$ & $18-19$ & $19-20$ & $20-21$ & $21-22$ & $22-23$ & $23-24$ \\
price & 27.06 & 26.81 & 26.23 & 26.36 & 26.43 & 26.8 & 27.26 & 28.2 & 28.97 & 29.5 & 28.68 & 27.1 \\
\hline
\end{tabular}


Table A3. Unit capacity limits.

\begin{tabular}{cc}
\hline Controlled Units & Constraint \\
\hline Utility & $(-50,50)$ \\
ESS & $(-40,40)$ \\
Fuel cell & $(0,50)$ \\
\hline
\end{tabular}

\section{References}

1. Aryani, D.R.; Song, H. Coordination Control Strategy for AC/DC Hybrid Microgrids in Stand-Alone Mode. Energies 2016, 36, 1-20. [CrossRef]

2. Li, C.; de Bosio, F.; Chaudhary, S.K.; Graells, M.; Vasquez, J.C.; Guerrero, J.M. Operation cost minimization the droop-controlled DC microgrids based on real-time pricing and optimal power flow. In Proceedings of the IECON 2015-41st Annual Conference of the IEEE Industrial Electronics Society, Yokohama, Japan, 9-12 November 2015; pp. 3905-3909.

3. Guerrero, J.M.; Vasquez, J.C.; Matas, J.; de Vicuña, L.G.; Castilla, M. Hierarchical control of droop-controlled AC and DC microgrids-A general approach toward standardization. IEEE Trans. Ind. Electron. 2011, 58, 158-172. [CrossRef]

4. Lu, X.; Wan, J. Modeling and control of the distributed power converters in a standalone DC microgrid. Energies 2016, 9, 217. [CrossRef]

5. Riccobono, A.; Ferdowsi, M.; Hu, J.; Wolisz, H.; Jahangiri, P.; Müller, D.; De Doncker, R.W.; Monti, A. Next generation automation architecture for DC smart homes. In Proceedings of the 2016 IEEE International Energy Conference (ENERGYCON), Leuven, Belgium, 4-8 April 2016.

6. Li, C.; Chaudhary, S.K.; Dragicevic, T.; Vasquez, J.C.; Guerrero, J.M. Power flow analysis for DC voltage droop controlled DC microgrids. In Proceedings of the 2014 11th International Multi-Conference on Systems, Signals \& Devices (SSD), Barcelona, Spain, 11-14 February 2014.

7. Email, D. Intelligent DC Microgrid Living Laboratories-A Chinese-Danish Cooperation Project. In Proceedings of the 2015 IEEE First International Conference on DC Microgrids (ICDCM), Atlanta, GA, USA, 7-10 June 2015; pp. 365-370.

8. Rahimi, B.F.; Ipakchi, A. Using a Transactive Energy Framework: Providing Grid Services from Smart Buildings. IEEE Electr. Mag. 2016, 4, 23-29. [CrossRef]

9. Pratt, B.A.; Krishnamurthy, D.; Ruth, M. Transactive Home Energy Management Systems. IEEE Electr. Mag. 2016, 4, 8-14. [CrossRef]

10. Akter, M.N.; Mahmud, M.A.; Oo, A.M.T. A hierarchical transactive energy management system for microgrids. In Proceedings of the 2016 IEEE Power and Energy Society General Meeting, Boston, MA, USA, 17-21 July 2016; pp. 1-5.

11. Amin, U.; Ieee, S.M.; Hossain, M.J.; Ieee, S.M.; Lu, J.; Ieee, S.M. Cost-Benefit Analysis for Proactive Consumers in a Microgrid for Transactive Energy Management Systems. In Proceedings of the 2016 Australasian Universities Power Engineering Conference (AUPEC), Brisbane, Australia, 25-28 Septemper 2016; pp. $25-28$.

12. World's First Blockchain-Managed Energy Transaction. Available online: http://www.theepochtimes. $\mathrm{com} / \mathrm{n} 3 / 2027695$-worlds-first-peer-to-peerenergy-transaction-on-the-blockchain-has-arrived/ (accessed on 6 July 2016).

13. Akter, M.N.; Mahmud, M.A.; Oo, A.M.T. Comprehensive economic evaluations of a residential building with solar photovoltaic and battery energy storage systems: An Australian case study. Energy Build. 2017, 138, 332-346. [CrossRef]

14. Han, Y.; Chen, W.; Li, Q. Energy Management Strategy Based on Multiple Operating States for a Photovoltaic/Fuel Cell/Energy Storage DC Microgrid. Energies 2017, 10, 136. [CrossRef]

15. Meng, L.; Sanseverino, E.R.; Luna, A.; Dragicevic, T.; Vasquez, J.C.; Guerrero, J.M. Microgrid supervisory controllers and energy management systems: A literature review. Renew. Sustain. Energy Rev. 2016, 60, 1263-1273. [CrossRef]

16. Khodayar, M.E.; Manshadi, S.D.; Vafamehr, A. The short-term operation of microgrids in a transactive energy architecture. Electr. J. 2016, 10, 41-48. [CrossRef] 
17. Nunna, H.S.V.S.K.; Doolla, S. Energy Management in Microgrids Using Demand Response and Distributed Storage-A Multiagent Approach. IEEE Trans. Power Deliv. 2013, 28, 939-947. [CrossRef]

18. Kim, T.; Yun, J.; Qiao, W. A multiagent system for residential DC microgrids. In Proceedings of the 2015 IEEE Power \& Energy Society General Meeting, Denver, CO, USA, 26-30 July 2015.

19. Dou, C.; Yue, D.; Han, Q.; Guerrero, J.A. Multi-Agent System Based Event-Triggered Hybrid Control Scheme for Energy Internet. IEEE Access 2017, 3536, 3263-3272. [CrossRef]

20. Sakib, N.; Hossain, J.; Ibrahim Bulbul, H.; Hossain, E.; Bayindir, R. Implementation of Unit Commitment Algorithm: A Comprehensive Droop Control Technique to Retain Microgrid Stability. In Proceedings of the 2016 IEEE International Conference on Birmingham Renewable Energy Research and Applications (ICRERA), Birmingham, UK, 20-23 November 2016.

21. Vasquez, J.C.; Guerrero, J.M.; Luna, A.; Rodriguez, P.; Teodorescu, R. Adaptive Droop Control Applied to Voltage-Source Inverters Operating in Grid-Connected and Islanded Modes. IEEE Trans. Ind. Electron. 2009, 56, 4088-4096. [CrossRef]

22. Dragicevic, T.; Guerrero, J.M.; Vasquez, J.C.; Skrlec, D. Supervisory control of an adaptive-droop regulated DC microgrid with battery management capability. IEEE Trans. Power Electron. 2014, 29, 695-706. [CrossRef]

23. Eom, J.; Park, L.; Na, W.; Dao, N.N.; Jang, S.M.; Kim, Y.H.; Lee, J.W.; Sungrae, C. Using social Internet of Things (SIoT) demand side management on the plant. In Proceedings of the 2016 Eighth International Conference on Ubiquitous and Future Networks (ICUFN), Vienna, Austria, 5-8 July 2016; pp. 685-687.

24. Aldhaheri, A.; Etemadi, A. Impedance Decoupling in DC Distributed Systems to Maintain Stability and Dynamic Performance. Energies 2017, 10, 470. [CrossRef]

25. Lu, X.; Liu, N.; Chen, Q.; Zhang, J. Multi-objective Optimal Scheduling of a DC Micro-grid Consisted of PV System and EV Charging Station. In Proceedings of the 2014 IEEE Innovative Smart Grid Technologies-Asia (ISGT Asia), Kuala Lumpur, Malaysia, 20-23 May 2014; pp. 487-491.

26. Xu, Y.; Zhang, W.; Hug, G.; Kar, S.; Li, Z. Cooperative Control of Distributed Energy Storage Systems in a Microgrid. IEEE Trans. Smart Grid. 2015, 6, 238-248. [CrossRef]

27. Chen, H.; Liu, Z.; Coskun, A.K.; Wierman, A. Optimizing energy storage participation in emerging power markets. In Proceedings of the 2015 Sixth International Green Computing Conference and Sustainable Computing Conference (IGSC), Las Vegas, NV, USA, 14-16 December 2015.

28. Intelligent DC Microgrid Living Lab. Available online: http://www.et.aau.dk/research-programmes/ microgrids/activities/intelligent-dc-microgrid-living-lab/ (accessed on 15 January 2017).

29. Olivares, D.E.; Lara, J.D.; Canizares, C.A.; Kazerani, M. Stochastic-Predictive Energy Management System for Isolated Microgrids. IEEE Trans. Smart Grid 2015, 6, 2681-2693. [CrossRef]

30. Moschakis, M.N.; Karfopoulos, E.L.; Zountouridou, E.I.; Papathanassiou, S.A. On Adaptation of Electric Vehicle and Microgrid Issues to EMC-Power Quality Standards. Electr. Electron. Eng. J. 2012, 2, $249-257$.

31. Zhou, C.; Qian, K.; Allan, M.; Zhou, W. Modeling of the cost of EV battery wear due to V2G application in power systems. IEEE Trans. Energy Convers. 2011, 26, 1041-1050. [CrossRef] 